The final authenticated version is available online at https://doi.org/10.1007/978-3-030-83164-6_11

Nyembe B.Z.M., Howard G.R. (2021) WhatsApp, an Educational Computer System?. In: Bentahar J., Awan I., Younas M., Grønli TM. (eds) Mobile Web and Intelligent Information Systems. MobiWIS 2021. Lecture Notes in Computer Science, vol 12814. Springer, Cham. https://doi.org/10.1007/978-3-030-83164-6_11

\title{
WhatsApp, an Educational Computer System?
}

\author{
Bangisisi Z. M. Nyembe ${ }^{1}$ and Grant R. Howard ${ }^{2[0000-0002-9506-8504]} \square$ \\ ${ }^{1}$ University of South Africa (Unisa), Florida, South Africa \\ 54830222 emylife.unisa.ac.za \\ ${ }^{2}$ University of South Africa (Unisa), Florida, South Africa \\ howargreunisa.ac.za
}

\begin{abstract}
.
Can WhatsApp be used as an educational computer system? This question had not been answered conclusively by current research and was a global imperative for the computers and education research and practice communities given that over a quarter of the entire world's population used WhatsApp. To advance the field, educational theory and practice and to give meaning to WhatsApp in education, empirical quantitative evidence was gathered with a questionnaire to measure mobile collaborative learning on WhatsApp. The results indicated that increased collaboration on WhatsApp improved academic achievement and improving other key aspects such as active learning, trust, support, formality, interaction and interdependence enhanced collaboration and, in turn, improved academic achievement. The study advanced educational computer theory and mobile collaborative learning theory and provided evidence-based learning design guidelines for incorporating WhatsApp into learning programs for improved academic achievement.
\end{abstract}

Keywords: Cooperative/collaborative learning, Mobile learning, Post-secondary education, Social Media, 21st century abilities

\section{Introduction}

The study asked the question, can WhatsApp be used as an educational computer system? This question was significant and relevant to educators and domain researchers globally, since there were about two billion active WhatsApp users globally as at October 2020, which made WhatsApp most widespread social media application behind Facebook and YouTube [1] and accounted for over a quarter of the entire world's population. This included students throughout the global tertiary education community and offered educators worldwide a free-to-use computer system with a large student user base that was already familiar with the application.

To this end, theory development by the research community is necessary to inform educational practice about the design, not specifically WhatsApp software design but educational program and activity design on WhatsApp, and use decisions required for realizing an effective WhatsApp educational computer system. 
Recent research has begun to develop such theory, but to date it remains ambivalent, as is evident in contrasting research reporting that WhatsApp may improve learning [24] and WhatsApp may not [5-7]. Thus, conducting scientific research on and developing theory relating to WhatsApp and academic achievement was essential for advancing the field of computers and education and its sub-fields of social media and academic achievement, mobile collaborative learning (MCL) and mobile learning (m-learning). Furthermore, the study builds requisite meaning among the international research and education communities, where evidence-based knowledge is produced on the relationships between technological progress and educational goals. Following a positivistic epistemology, the study develops original knowledge to answer the research question by gathering quantitative data using a questionnaire from relevant students.

The study advances current research. It addresses questions about the role of social media in supporting academic goals and responds to the requests for new research on the use of social media applications and their impact on academic achievement [8], it explores situated social media practices contextualized within a specific social media platform [9], it sets out to test whether generalized findings about social media and academic performance hold for WhatsApp [10] and it investigates MCL using WhatsApp [11, 12].

This section stated the study's problem, question and objective and explained its significance and contribution to the research field, educational practice and theory advancement. Following is the rigorous instrument development process and initial structural model. Section Three details the rigorous empirical method for answering the research question and provides guidance for replication studies. Section Four presents the study's results and explores their implications. Section Five clarifies the study's contribution to theory progression, exposes the study's limitations and offers opportunities for further advancement of the field.

\section{Theoretical framework}

Without there being any prior research on the specific constructs and their interrelationships, theoretical framework, involved in MCL on WhatsApp and academic achievement, the study proceeded to review and evaluate instruments in the literature that measured collaboration from various fields and perspectives. Those that had high reliability, applicability and construct validity were retained and input into the instrument development process, which was guided by the MacKenzie et al. [13] scale development framework. The process resulted in a theoretical framework of ten constructs applicable to the research problem with six measurement items per construct and an initial structural model (see Fig. 1) [14]. The ten constructs were Active Learning (AL), Support (S), Interdependence (ID), Interaction (IA), Formality (F), Sense of Community (SC), Trust (T), Information Exchange (IE), Collaboration (C) and self-reported Academic Achievement (AA). 
The study defined each of the constructs as follows. Support (S) is the level of learning-related assistance and help that is provided to a student by other students on WhatsApp. Interaction (IA) is the level of learning-related engagement and reciprocal action, such as sharing, discussing, meeting and chatting, between two or more students on WhatsApp. Sense of Community (SC) is the level of belonging to a WhatsApp learning-related group having common goals, needs and interests. Information Exchange (IE) is the level of learning-related information exchanged during learning on WhatsApp. Interdependence (ID) is the level of condition or contingency on other students for learning on WhatsApp. Active Learning (AL) is the level of WhatsApp learning activities involving meaningful and applied learning activities and is contrasted with passive learning. Formality (F) is the level of serious and academically correct learning-related engagement on WhatsApp between students by virtue of their language in contrast to relaxed and casual engagement. Trust $(\mathrm{T})$ is the level of confidence that a student has in other students when learning on WhatsApp. Collaboration (C) is the level of contributing and working jointly on WhatsApp to attain shared learning goals. Academic Achievement (AA) is typically measured by actual student grades obtained from writing a test or examination [15]. However, the study could not obtain access to actual grade information for each of the respondents and therefore defined Academic Achievement (AA) as the level of a student's self-reported academic achievement.

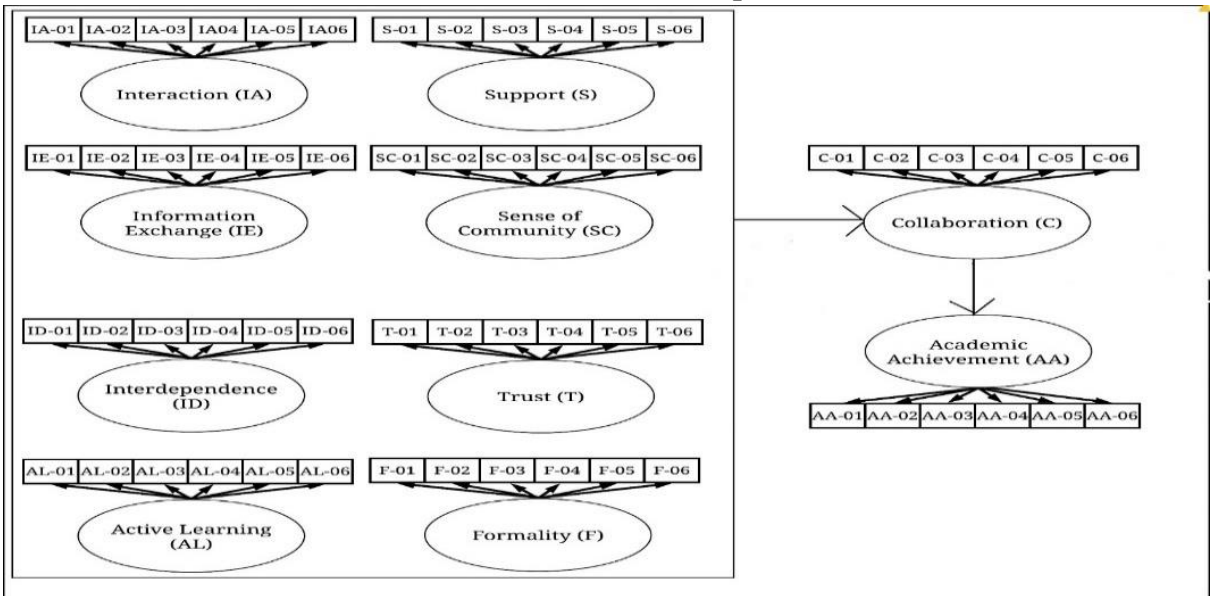

Fig. 1. Initial measurement and structural model.

Since there was no knowledge or theoretical framework available in the literature that specified how these constructs interrelated and it was clear from the literature evaluation that these were key constructs involved in collaboration and collaboration on WhatsApp, the study, at this point, hypothesized that Collaboration (C) influences selfreported Academic Achievement (AA) and the other eight constructs influence Collaboration (C). These hypotheses are described in the study's initial structural model (see Fig. 1). 


\section{Method}

\subsection{Strategy and sampling}

The study followed a rigorous positivistic research pattern where primary empirical quantitative data was collected using a questionnaire [16]. The data was gathered from students in two English medium tertiary education institutions located in the Free State province in South Africa. Judgement/purposive sampling was used to select respondents that matched the profile required to address the research problem [17]. The respondents included undergraduate (first- to third-year level) and honours (fourth-year level) students. The sampled students provided relevant data from both academic and vocational qualifications and many different qualification types for breadth of student characteristics and representativeness.

Before any data was collected, written permission was obtained from each of the institutions, ethical clearance was obtained from the researchers' university and each respondent was required to acknowledge informed consent before submitting their questionnaire responses.

Data collection for the main study began in late April 2020 and ended in mid-October 2020 with 393 completed and usable responses from the anonymous Google Forms online questionnaire. 393 responses were considered adequate to address the research problem using structural equation modelling (SEM) since at least two-hundred responses is generally considered enough for effective SEM analysis [18].

\section{$4 \quad$ Results and discussion}

\subsection{Reliability}

To test the questionnaire's reliability, a pilot study was conducted in early April 2020 with data from sixteen representative students. The data was analyzed with JASP's single-test reliability analysis. JASP was a free multi-platform open-source statistics package implemented in $\mathrm{R}$ and a series of $\mathrm{R}$ packages and developed and continually updated by researchers at the University of Amsterdam [19]. Subsequently, questionnaire items were amended and/or dropped, which resulted in improved Cronbach's alpha values and acceptable reliability of the final set of questionnaire items [20]. Thereafter, the main study was conducted and the Cronbach's alpha values for each construct based on the main study data are provided in Table 1 .

Table 1. Cronbach's alpha reliability analysis - main study.

\begin{tabular}{ll}
\hline Construct & Cronbach Alpha \\
\hline (AA) Academic Achievement & 0.946 \\
(S) Support & 0.927 \\
(IE) Information Exchange & 0.925 \\
(SC) Sense of Community & 0.923 \\
(C) Collaboration & 0.914 \\
(AL) Active Learning & 0.899
\end{tabular}




\begin{tabular}{ll}
\hline Construct & Cronbach Alpha \\
\hline (T) Trust & 0.888 \\
(IA) Interaction & 0.884 \\
(F) Formality & 0.862 \\
(ID) Interdependence & 0.821 \\
\hline
\end{tabular}

\subsection{Data handling}

Once the main study data had been collected, data cleaning was performed to identify and address any errors or inconsistencies due to corrupted data or inaccurate data entry. The only changes that were made to the data were in the respondent characteristics section of the questionnaire. These changes included correcting misspelled home languages, modifying the spelling and descriptions of qualifications, and similar. All changes maintained the original meaning of the data. Once cleaned, the data was imported into JASP for all subsequent statistical analyses.

\subsection{Respondent characteristics}

Almost two-thirds of the students were female, most students were between the ages of 19 and 24 years old, most of the respondents spoke Sesotho and isiZulu, over eighty percent were registered for bachelor's degrees with a comparatively even distribution across first to fourth year course levels and over a third spent from one to five hours per week on WhatsApp learning with other students. In addition, most students used smartphones at home to learn on WhatsApp and the most frequent barriers to learning on WhatsApp were the cost of data, places with no signal for internet connectivity, places without electrical plug points for charging their devices and places without freely available Wi-Fi hotspots.

\subsection{Exploratory factor analysis (EFA)}

Exploratory factor analysis (EFA) is a statistical technique for exploring the underlying factor structure in a data set and was used to demonstrate whether the items in the questionnaire loaded onto the research model constructs [21] and to assess construct, convergent, discriminant and face validity [22].

Prior to conducting the EFA, a Kaiser-Meyer-Olkin (KMO) test was performed to assess the data set's suitability for EFA. The overall KMO value calculated was 0.95 , which demonstrated strong correlation among the items and justified proceeding with the EFA.

Initially, Principal Component Analysis (PCA) was run with varimax rotation, since it is a widely used variable-reduction technique that results in a concise number of principal components with eigenvalues above one [23] and that represent the majority of the variance within the data set [21]. The outcome was nine principal components (see Table 2). 
Table 2. Principal component characteristics.

\begin{tabular}{lrrr}
\hline No. & Eigenvalue & Proportion var. & \multicolumn{2}{c}{ Cumulative } & \\
\hline PC1 & 18.037 & 0.451 & 0.451 \\
PC2 & 2.619 & 0.065 & 0.516 \\
PC3 & 2.107 & 0.053 & 0.569 \\
PC4 & 1.772 & 0.044 & 0.613 \\
PC5 & 1.538 & 0.038 & 0.652 \\
PC6 & 1.351 & 0.034 & 0.686 \\
PC7 & 1.270 & 0.032 & 0.717 \\
PC8 & 1.064 & 0.027 & 0.744 \\
PC9 & 1.016 & 0.025 & 0.769 \\
\hline
\end{tabular}

The PCA indicated that only nine principal components accounted for most of the variance in the data, instead of the expected ten per the initial measurement and structural model. In addition, the PCA calculated the loadings of each questionnaire item onto the nine principal components. A factor loading of above 0.4 is generally regarded as a good loading [24], so loadings less than or equal to 0.4 were excluded from the analysis. Based on the PCA, it was decided to drop the construct Sense of Community (SC) as it was evident that all four items relating to SC loaded onto both components PC1 and PC4. However, PC1 also had all four items relating to the construct Support (S) loaded onto it, but with higher loadings than any of the SC items and PC4 also had all four items relating to the construct Active Learning (AL) loaded onto it, but with higher loadings than any of the SC items. This indicated that the SC items and SC construct could be removed since they did not load uniquely and had weaker loadings than the other construct items that loaded onto PC1 and PC4. The construct Sense of Community (SC) was removed from the initial measurement and structural model and all data relating to the four Sense of Community (SC) items were excluded from further analyses [24].

Thereafter, the often preferred EFA method called Principal Axis Factoring (PAF) [21] with varimax rotation and loadings above 0.4 was conducted based on nine factors indicated during PCA. The PAF demonstrated that each construct's set of four questionnaire items loaded onto a separate factor, which provided support for using the nineconstruct model for the subsequent analyses.

\subsection{Analysis of variance (ANOVA)}

\subsubsection{Objectives and requirements}

To determine if there were any significant systematic variances present in any of the respondent characteristics, such as age or course level, ANOVA was run [25]. Significant systematic variances can provide valuable insights and potentially inform educators about how to structure their teaching with WhatsApp.

Homogeneity of variance is an important assumption of ANOVA, which was determined with Levene's tests. If the p-value for this test was greater than or equal to 0.05 $(p \geq 0.05)$, there was no violation of the homogeneity of variance assumption. However, 
where $\mathrm{p}<0.05$, there was a violation, and ANOVA was not conducted because any interpretation could be misleading.

In addition, ANOVA is an omnibus test that simultaneously tests all possible comparisons to assess whether a statistically significant difference exists amongst any groups, but it cannot specify which groups differ. Specifying the groups that are significantly different required the Tukey's post hoc test, which necessitates a greater difference to establish significance since it controls for Type I errors or a true null hypothesis being rejected.

\subsubsection{Gender, age range, home language, qualification, course level and hours on WhatsApp every week learning}

Focusing on the gender of the respondents, the Levene's test indicated that ANOVA could proceed for constructs IA, S, ID, T, AL, IE, C and AA ( $p \geq 0.05$ ). However, the ANOVA produced no significant differences on any construct for gender $(\mathrm{p} \geq 0.05)$. Notably, since the respondents entered either male or female only for gender, an independent samples t-test could have been conducted for each construct to determine any significant differences. This was done for completeness, and the $\mathrm{t}$-tests confirmed no significant differences for gender $(\mathrm{p} \geq 0.05)$.

Regarding the age range of the respondents, the Levene's test indicated that ANOVA could proceed for constructs IA, S, ID, T, AL, F, IE C and AA $(p \geq 0.05)$ and the ANOVA indicated that there were significant differences $(p<0.05)$ on the constructs IA, T, AL, IE and C only.

For construct IA, T and AL, Tukey's test showed that there were significant differences $(p<0.05)$ between the groups 19 to 24 years old and 35 to 39 years old and between the groups 25 to 29 years old and 35 to 39 years old, which suggests that the 35 to 39 years old age group interacted, trusted and actively learned less on WhatsApp than the younger groups as was evident by their lower mean score for these constructs.

For construct IE, Tukey's test showed a significant difference $(\mathrm{p}<0.05)$ between the groups 25 to 29 years old and 35 to 39 years old, which suggests that the 35 to 39 years old age group exchanged less information on WhatsApp than the younger group as was evident by their lower mean score for the IE construct.

However, for construct C, Tukey's test showed no significant differences between any of the groups $(\mathrm{p} \geq 0.05)$. Overall, the ANOVA suggests that the 35 to 39 years old age group, who represented less than $1 \%$ of the respondents, may have trusted less on WhatsApp and interacted, actively learnt and exchanged less information than some of the younger groups. Notably, this age group could be at any course level, from first year to fourth year, so these results are independent of the course level findings.

For the home language of the respondents, the Levene's test indicated that ANOVA could proceed for constructs IA, S, T, AL, F, IE, C and AA ( $p \geq 0.05$ ). Subsequently, the ANOVA indicated that there was a significant difference $(p<0.05)$ on the construct AA only and Tukey's test showed a significant difference between the language groups Sesotho sa Leboa and Setswana only for this construct $(\mathrm{p}<0.05)$. While it was not clear why there was a significant difference on academic achievement specifically between 
these two languages and none of the other languages, the descriptive statistics showed that Sesotho sa Leboa had a mean of 10.82 and a standard deviation of 4.81 and Setswana had a mean of 18.10 and a standard deviation of 2.38. Nevertheless, these two languages accounted for only $5.3 \%$ of the respondents and further studies with much larger samples of these specific language speakers would be required to investigate whether this finding was valid across their broad populations.

In terms of the qualifications, the Levene's test indicated that ANOVA could proceed for constructs IE, $\mathrm{C}$ and AA $(\mathrm{p} \geq 0.05)$. However, the ANOVA indicated that there were significant differences $(\mathrm{p}<0.05)$ on the constructs IE and AA only and Tukey's test showed significant differences for the construct IE only $(\mathrm{p}<0.05)$.

Tukey's test showed significant differences for the construct IE between each of the qualifications Bachelor of Science (BSc), Bachelor of Education (BEd), Bachelor of Social Sciences (BSocSci), Bachelor of Arts (BA), Postgraduate Certificate in Education (FET) (PGCE) and the group Various other bachelor's and honours degrees, diplomas and certificates (VoDDC). This may be suggestive of information volume differences between the more traditional bachelor's degrees and the various other bachelor's and honours degrees, diplomas and certificates, since the VoDDC group had a lower mean score on information exchange.

With reference to course level, the Levene's test indicated that ANOVA could proceed for constructs IA, S, ID, AL, IE and C ( $p \geq 0.05)$. The ANOVA indicated that there were significant differences $(p<0.05)$ on the constructs IA, S, IE and C only and Tukey's test agreed on those four constructs $(\mathrm{p}<0.05)$.

For the IA and IE constructs, Tukey's test showed a significant difference between first-year level and third-year level, with third-year level having a higher mean construct score. For the S construct Tukey's test showed significant differences first-year level and third-year level and between third-year level and fourth-year level, with thirdyear level having the highest mean construct score.

For the C construct Tukey's test showed significant differences between first-year level and third-year level, between first-year level and fourth-year level and between second-year level and third-year level, with third-year level having the highest mean construct score followed by the second-year level then the fourth-year level and finally the first-year level. These results suggest that the more advanced third-year students, who represented almost a third of the respondents, made more use of WhatsApp to interact, support, exchange information and collaborate.

In relation to the hours spent on WhatsApp every week learning, the Levene's test indicated that ANOVA could proceed for constructs IA, ID, F, IE, C and AA ( $p \geq 0.05)$. ANOVA indicated that there were significant differences $(p<0.05)$ on the constructs IA, ID, F, IE and C only and Tukey's test agreed $(\mathrm{p}<0.05)$.

Tukey's test showed significant differences for the constructs IA and ID between group $0-<1$ hour and group $10-<20$ hours and between group $0-<1$ hour and group $40+$ hours, with the group $0-<1$ hour having the highest mean construct score. 
For the construct $\mathrm{F}$, Tukey's test showed significant differences between group 0 $<1$ hour and group $20-<40$ hours and between group $0-<1$ hour and group $40+$ hours, with the group $0-<1$ hour having the highest mean construct score.

For the construct IE, Tukey's test showed significant differences between group $0-$ $<1$ hour and each of groups $1-<5$ hours, $5-<10$ hours, $10-<20$ hours, $20-<40$ hours and $40+$ hours, with the group $0-<1$ hour having the highest mean construct score.

In addition, for the construct $\mathrm{C}$, Tukey's test showed significant differences between group $0-<1$ hour and each of groups $5-<10$ hours, $10-<20$ hours, $20-<40$ hours and $40+$ hours, with the group $0-<1$ hour having the highest mean construct score.

These results suggest that the students who spend between $0-<1$ hour on WhatsApp every week learning, experience the most interaction, information exchange, collaboration, formality and interdependence.

\subsection{Structural equation modeling (SEM)}

\subsubsection{Objectives and software}

To test and evaluate the research model hypotheses, measure the relationships amongst the constructs and answer the research question, SEM was conducted. The SEM was processed in JASP, whose SEM module was based on the lavaan package in $\mathrm{R}[26,27]$, which was a free open-source commercial-quality statistical package for latent variable modeling.

\subsubsection{Initial SEM structural model specification}

The initial SEM structural model was specified using the following hypothesized interrelationships and processed using the maximum likelihood (ML) method: Trust (T), Interaction (IA), Interdependence (ID), Support (S), Information Exchange (IE), Formality (F) and Active Learning (AL) influences Collaboration (C) and Collaboration (C) influences Academic Achievement (AA).

However, the $\chi^{2}$ (absolute/predictive fit Chi-square), RMSEA (root mean square error of approximation) and TLI (Tucker-Lewis index) or NNFI (non-normed fit index) model fit indices (MFIs) were not at acceptable levels and MFIs are necessary to support claims that the theoretical and structural relations adequately agree with the observed data [28]. Thus, the SEM structural model required re-specification.

\subsubsection{Re-specified SEM structural model}

Re-specification of the SEM structural model was done to achieve acceptable MFIs and to ensure that the interrelationships between Active Learning (AL), Formality (F), Interaction (IA), Support (S), Information Exchange (IE), Trust (T) and Interdependence (ID) were measured.

The re-specification was guided by the modification indices calculated in JASP. Modification indices indicate whether changes such as adding paths to the SEM structural model would result in improvements and is the Chi-square $\left(\chi^{2}\right)$ value by which the 
model fit would improve if the changes were made [29]. Table 3 provides the model fit indices for the re-specified SEM structural model.

Table 3. Re-specified SEM structural model - MFIs.

\begin{tabular}{llll}
\hline MFI & Recommended limit & Calculated value & Acceptable fit? \\
\hline $\begin{array}{l}\chi^{2} \text { (absolute/predictive fit Chi- } \\
\text { square) }\end{array}$ & $\leq 3.0$ & 2.905 & Yes \\
$\begin{array}{l}\text { SRMR (standardized root } \\
\text { mean square residual) }\end{array}$ & $\leq 0.8$ & 0.045 & Yes \\
$\begin{array}{lll}\text { RMSEA (root mean square er- } \\
\text { ror of approximation) }\end{array}$ & $<0.06$ to 0.08 with & $\begin{array}{l}0.070(90 \% \text { confi- } \\
\text { dence interval = }\end{array}$ & Yes \\
CFI (comparative fit index) & $\geq 0.95$ & $0.045-0.095)$ & \multirow{2}{*}{ Yes } \\
TLI (Tucker-Lewis index) or & $\geq 0.95$ can be 0 > TLI & 0.984 & Yes \\
NNFI (non-normed fit index) & $>1$ for acceptance & 0.961 & Yesterval \\
\hline
\end{tabular}

Given the many significant relationships in the re-specified SEM structural model, it is split into two diagrams also for visual ease, namely Diagram One and Diagram Two. Diagram One is presented in Fig. 2 and shows how the other constructs influence Collaboration (C) and how Collaboration (C) influences Academic Achievement (AA). Fig. 2 excludes the interrelationships among the constructs Active Learning (AL), Formality (F), Interaction (IA), Support (S), Information Exchange (IE), Trust (T) and Interdependence (ID). Diagram One suggests that Collaboration (C) had a strong positive influence on Academic Achievement (AA), Active Learning (AL) had a moderate positive influence on Collaboration $(C)$ and the other constructs with solid lines had weak positive influences on Collaboration (C).

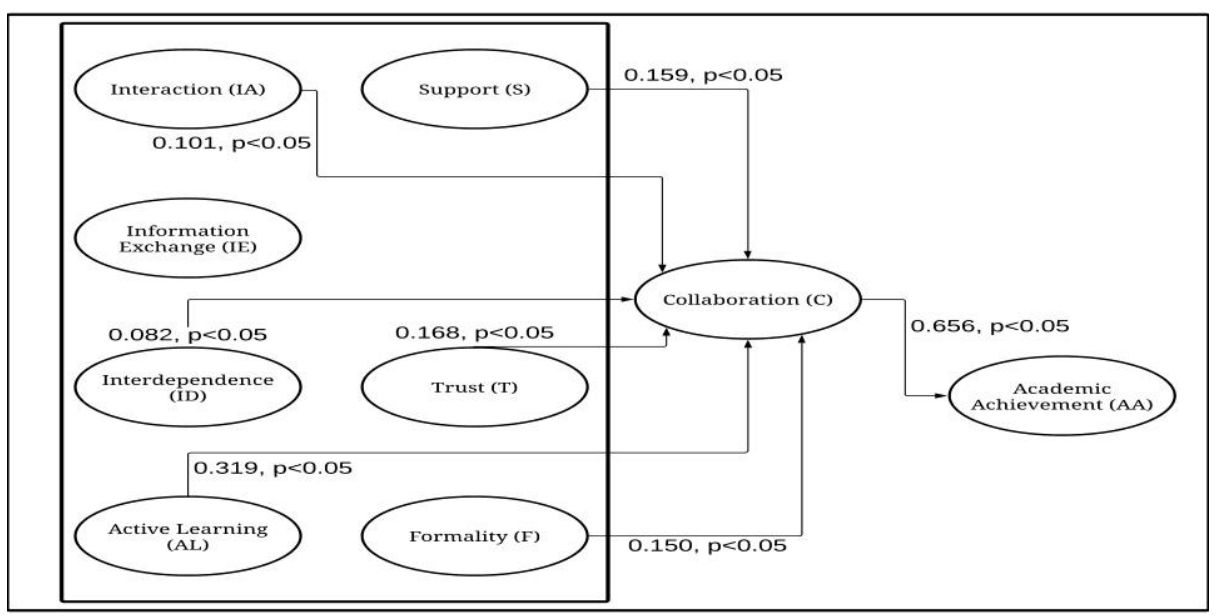

Fig. 2. Re-specified SEM structural model - Diagram One.

Diagram Two is presented in Fig. 3 and shows the influences amongst the constructs Active Learning (AL), Formality (F), Interaction (IA), Support (S), Information Exchange (IE), Trust (T) and Interdependence (ID). Diagram Two highlights that Formality $(\mathrm{F})$ and especially Trust $(\mathrm{T})$ were antecedent constructs that positively influenced the other constructs, while not influencing each other. This could be due to Trust (T) 
and Formality $(\mathrm{F})$ being constructs relating to necessary mental dispositions, in contrast to Active Learning (AL), Interaction (IA), Support (S) and Information Exchange (IE) that relate to subsequent actions. Diagram Two suggests that Trust (T) had a moderate to strong positive influence on Active Learning (AL), Interaction (IA), Support (S), Information Exchange (IE) and Interdependence (ID) while Formality (F) had a weak positive influence on Active Learning (AL) and Interdependence (ID). Thus, Trust (T) appeared to be an important requirement for all the constructs, while increased Formality (F) may be required for Active Learning (AL) and Interdependence (ID).

Support (S) did not influence any other constructs but was moderately positively influenced by Trust (T), Information Exchange (IE) and Interaction (IA), and weakly positively influenced by Active Learning (AL).

Active Learning (AL) had weak relationships with all the other constructs, except Trust (T), and was either influenced by or influencing them. Interaction (IA) had weak positive influences on Active Learning (AL), Support (S) and Information Exchange (IE), Information Exchange (IE) had a weak positive influence on Support (S) and Interdependence (ID) had a weak positive influence on Active Learning (AL).

Diagram Two supports the study's literature analysis and synthesis which indicated that these constructs were associated with collaboration. While the interrelationships exposed by the re-specified SEM structural model appear complex, they were theoretically justifiable both at face value and in terms of the literature and construct definitions. The SEM provided evidence of the important constructs and their interrelationships when learning with WhatsApp.

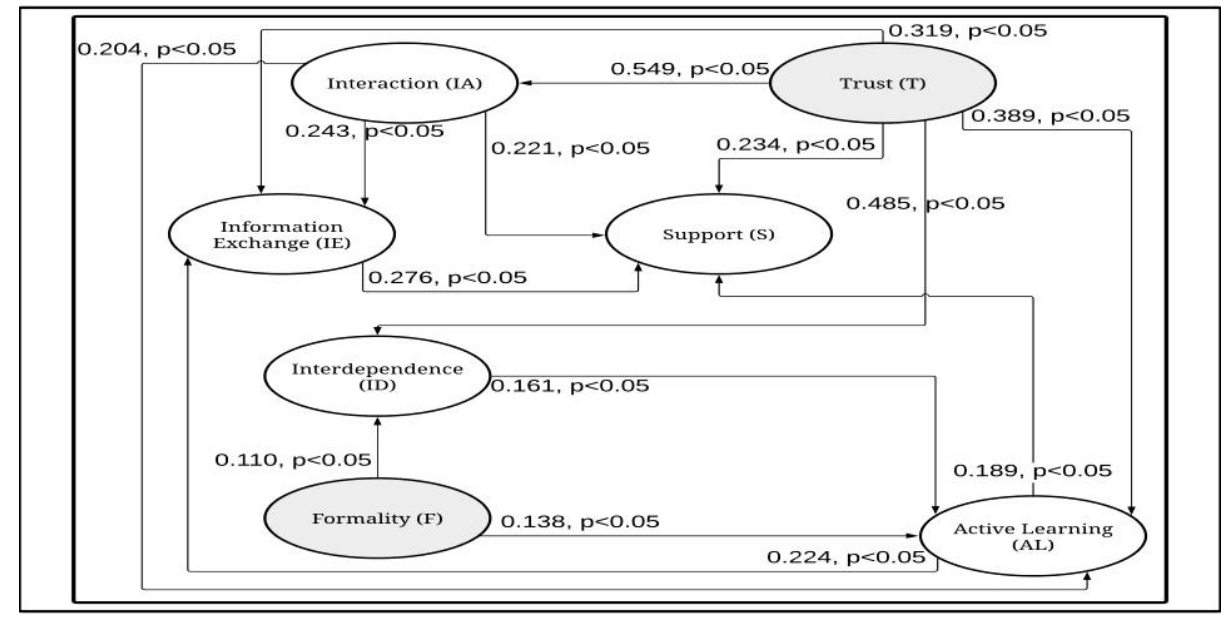

Fig. 3. Re-specified SEM structural model - Diagram Two.

SEM provided an efficient method for specifying and analyzing the interrelationships among the constructs and tested the hypothesized relationships. In particular, it was evident that collaboration had a strong positive influence on self-reported academic achievement, active learning a moderate positive influence on collaboration and trust a moderate to strong influence on all associated aspects including active learning. 


\section{Conclusion}

The study provided empirical evidence that WhatsApp can be used as an educational computer system, which answers an important global question and advances theory and educational practice, especially given the size of the WhatsApp user base and its availability worldwide in educational institutions.

The evidence that collaboration on WhatsApp improves academic achievement progresses and corroborates recent studies reporting that WhatsApp may improve learning [2-4]. Furthermore, in light of contrasting studies that WhatsApp may not improve learning [5-7], the study exposes a replicable, measurable and quantifiable epistemology for knowing key constructs and their interrelationships, the theory, involved in learning on WhatsApp. In addition, the study furthers understanding about how to design learning with WhatsApp for improved learning.

The study moves forward current research, theory and practice by responding to the request for new research on the use of social media applications and their impact on academic achievement [8], explored situated social media practices contextualized within a specific social media platform, namely WhatsApp [9], tested whether generalized findings about social media and academic performance hold for WhatsApp [10] and investigated MCL using WhatsApp $[11,12]$.

For teaching practice, the findings extend our comprehension of the key elements involved in learning on WhatsApp and provide insights into how these elements should be designed to produce an educational computer system and improve academic achievement. It would be important to design learning activities for a high level of collaboration on WhatsApp since there is a positive relationship between collaboration and academic achievement. Then, the design should consider the development and maintenance of trust and formality during learning activities on WhatsApp as these aspects are indicated as essential for improving active learning, support, interaction and interdependence, all of which influence collaboration. In addition, learning design should include specific activities that require students to actively learn, support one another, interact and foster interdependence as these would enhance collaboration and, in turn, improve academic achievement. Furthermore, educators should design learning activities differently for different course levels so that first- and second-year level students are encouraged more to interact, support, exchange information and collaborate during their learning activities, as third year students appear to require less encouragement. Also, it may be necessary to provide additional support to older students in the 35 to 39 years old age group, who may not trust learning activities on WhatsApp and interact, actively learn and exchanged less information than the younger groups. Interestingly, learning programs making use of WhatsApp should design for short periods on WhatsApp only, such as an hour per week, as these time periods appear to be the most constructive with high levels of interaction, information exchange, formality, interdependence and collaboration.

The study did have limitations, which expose new research opportunities. A limitation relates to the study's sampling method which, while rigorous, relevant and 
efficient, may constrain generalizability. Future studies could test and advance the theory developed in the study in and across different country, cultural, language and urban contexts. In addition, the study's data was gathered from respondents at one point in time, a cross-sectional study, and studying these phenomena on a longitudinal basis could expose new knowledge about the interactions amongst the research constructs and discover new patterns of student learning behavior.

\section{References}

1. Statista.com: Most popular social networks worldwide as of October 2020, ranked by number of active users, https://www.statista.com/statistics/272014/global-social-networks-ranked-bynumber-of-users/\#professional, last accessed 2021/01/17.

2. Pimmer, C., Brühlmann, F., Odetola, T.D., Oluwasola, D.O., Dipeolu, O., Ajuwon, A.J.: Facilitating professional mobile learning communities with instant messaging. Comput. Educ. 128, 102-112 (2019). https://doi.org/10.1016/j.compedu.2018.09.005.

3. Eid, M.I.M., Al-Jabri, I.M.: Social networking, knowledge sharing, and student learning: The case of university students. Comput. Educ. 99, 14-27 https://doi.org/10.1016/j.compedu.2016.04.007.

4. Rasheed, M.I., Malik, M.J., Pitafi, A.H., Iqbal, J., Anser, M.K., Abbas, M.: Usage of social media, student engagement, and creativity: The role of knowledge sharing behavior and cyberbullying. Comput. Educ. 159, 1-12 (2020). https://doi.org/10.1016/j.compedu.2020.104002.

5. Alkhalaf, A.M., Tekian, A., Park, Y.S.: The impact of WhatsApp use on academic achievement among Saudi medical students. Med. Teach. 40, S10-S14 (2018). https://doi.org/10.1080/0142159X.2018.1464652.

6. Whelan, E., Islam, A.K.M.N., Brooks, S.: Applying the SOBC paradigm to explain how social media overload affects academic performance. Comput. Educ. 143, 1-12 (2020). https://doi.org/10.1016/j.compedu.2019.103692.

7. Liebherr, M., Schubert, P., Antons, S., Montag, C., Brand, M.: Smartphones and attention, curse or blessing? - A review on the effects of smartphone usage on attention, inhibition, and working memory. Comput. Hum. Behav. Reports. 1, 1-8 (2020). https://doi.org/10.1016/j.chbr.2020.100005.

8. Lacka, E., Wong, T.C., Haddoud, M.Y.: Can digital technologies improve students' efficiency? Exploring the role of Virtual Learning Environment and Social Media use in Higher Education. Comput. Educ. 163, 1-11 (2021). https://doi.org/10.1016/j.compedu.2020.104099.

9. Manca, S., Bocconi, S., Gleason, B.: “Think globally, act locally": A glocal approach to the development of social media literacy. Comput. Educ. 160, 1-17 (2021). https://doi.org/10.1016/j.compedu.2020.104025.

10. Giunchiglia, F., Zeni, M., Gobbi, E., Bignotti, E., Bison, I.: Mobile social media usage and academic performance. Comput. Human Behav. 82, 177-185 (2018). https://doi.org/10.1016/j.chb.2017.12.041.

11. Fu, Q.-K., Hwang, G.-J.: Trends in mobile technology-supported collaborative learning: A systematic review of journal publications from 2007 to 2016. Comput. Educ. 119, 129-143 (2018). https://doi.org/10.1016/j.compedu.2018.01.004.

12. Kirschner, P.A., Sweller, J., Kirschner, F., Zambrano, J.: From cognitive load theory to 
collaborative cognitive load theory. Int. J. Comput. Collab. Learn. 13, 213-233 (2018). https://doi.org/10.1007/s11412-018-9277-y.

13. MacKenzie, S.B., Podsakoff, P.. M., Podsakoff, N.P.: Construct Measurement and Validation Procedures in MIS and Behavioral Research: Integrating New and Existing Techniques. MIS Q. 35, 293-334 (2011). https://doi.org/10.2307/23044045.

14. Nyembe, B.Z.M., Howard, G.R.: Development of a Quantitative Instrument to Measure Mobile Collaborative Learning (MCL) Using WhatsApp: The Conceptual Steps. Lect. Notes Comput. Sci. 12066, 507-519 (2020). https://doi.org/https://doi.org/10.1007/978-3-030-44999-5_42.

15. Allen, J.D.: Grades as valid measures of academic achievement of classroom learning. Clear. House A J. Educ. Strateg. Issues Ideas. 78, 218-223 (2005). https://doi.org/https://doi.org/10.3200/TCHS.78.5.218-223.

16. Sekaran, U., Bougie, R.: Research methods for business: A skill building approach. John Wiley \& Sons, Chichester, United Kingdom (2013).

17. Tongco, M.D.C.: Purposive sampling as a tool for informant selection. Ethnobot. Res. Appl. 5, 147-158 (2007). https://doi.org/10.17348/era.5.0.147-158.

18. Hoe, S.L.: Issues and procedures in adopting structural equation modelling technique technique. J. Appl. Quant. Methods. 3, 76-83 (2008). https://ink.library.smu.edu.sg/sis_research/5168

19. Love, J., Selker, R., Marsman, M., Jamil, T., Dropmann, D., Verhagen, J., Ly, A., Gronau, Q.F., Šmíra, M., Epskamp, S., Matzke, D., Wild, A., Knight, P., Rouder, J.N., Morey, R.D., Wagenmakers, E.-J.: JASP: Graphical statistical software for common statistical designs. J. Stat. Softw. 88, 1-17 (2019). https://doi.org/10.18637/jss.v088.i02.

20. Nunnally, J.C.: Psychometric theory. McGraw-Hill, New York (1976).

21. Costello, A.B., Osborne, J.: Best practices in exploratory factor analysis: Four recommendations for getting the most from your analysis. Pract. Assessment, Res. Eval. 10, 1-9 (2005). https://doi.org/10.7275/jyj1-4868.

22. Worthington, R.L., Whittaker, T.A.: Scale development research: A content analysis and recommendations for best practices. Couns. Pyschologist. 34, 806-838 (2006). https://doi.org/10.1177/0011000006288127.

23. Reinard, J.C.: Communication research statistics. Sage, Thousand Oaks, California (2006).

24. Howard, M.C.: A review of exploratory factor analysis decisions and overview of current practices: What we are doing and how can we improve? Int. J. Hum. Comput. Interact. 32, 51-62 (2016). https://doi.org/10.1080/10447318.2015.1087664.

25. Tredoux, C., Durrheim, K. eds: Numbers, Hypotheses \& Conclusions: A Course in Statistics for the Social Sciences. UCT Press, Cape Town, South Africa (2005).

26. Rosseel, Y.: lavaan: An R package for structural equation modeling. J. Stat. Softw. 48, 1-36 (2012). https://doi.org/10.18637/jss.v048.i02.

27. Rosseel, Y.: The lavaan tutorial, https://lavaan.ugent.be/tutorial/index.html, last accessed 2021/05/25.

28. Schreiber, J.B., Nora, A., Stage, F.K., Barlow, E.A., King, J.: Reporting structural equation modeling and confirmatory factor analysis results: A review. J. Educ. Res. 99, 323-338 (2006). https://doi.org/10.3200/JOER.99.6.323-338.

29. Whittaker, T.A.: Using the modification index and standardized expected parameter change for model modification. J. Exp. Educ. 80, 26-44 (2012). https://doi.org/10.1080/00220973.2010.531299. 